\title{
Stress fracture of the sixth rib in a canoeist
}

\author{
N. Maffulli MD ${ }^{1}$ and E. Pintore $M^{2}$ \\ ${ }^{1}$ Institute of Child Health, Respiratory and Anaesthetic Unit, Sports Medicine Laboratory, London and \\ Department of Orthopaedics, The Hospital for Sick Children, Great Ormond Street, London, UK \\ ${ }^{2}$ Departement d'Orthopedie et Traumatologie, Centre Hospitalier d'Annecy, Annecy, France
}

A 22-year-old Caucasian male canoeist of regional standard presented with non-radiating left sided chest pain which had arisen during a period of intensive water training. A physiotherapist had treated this as intercostal muscle strain without improvement.

Clinical examination showed only pain on forced expiration and tenderness over the insertion of the left serratus anterior. His pain was reproduced over

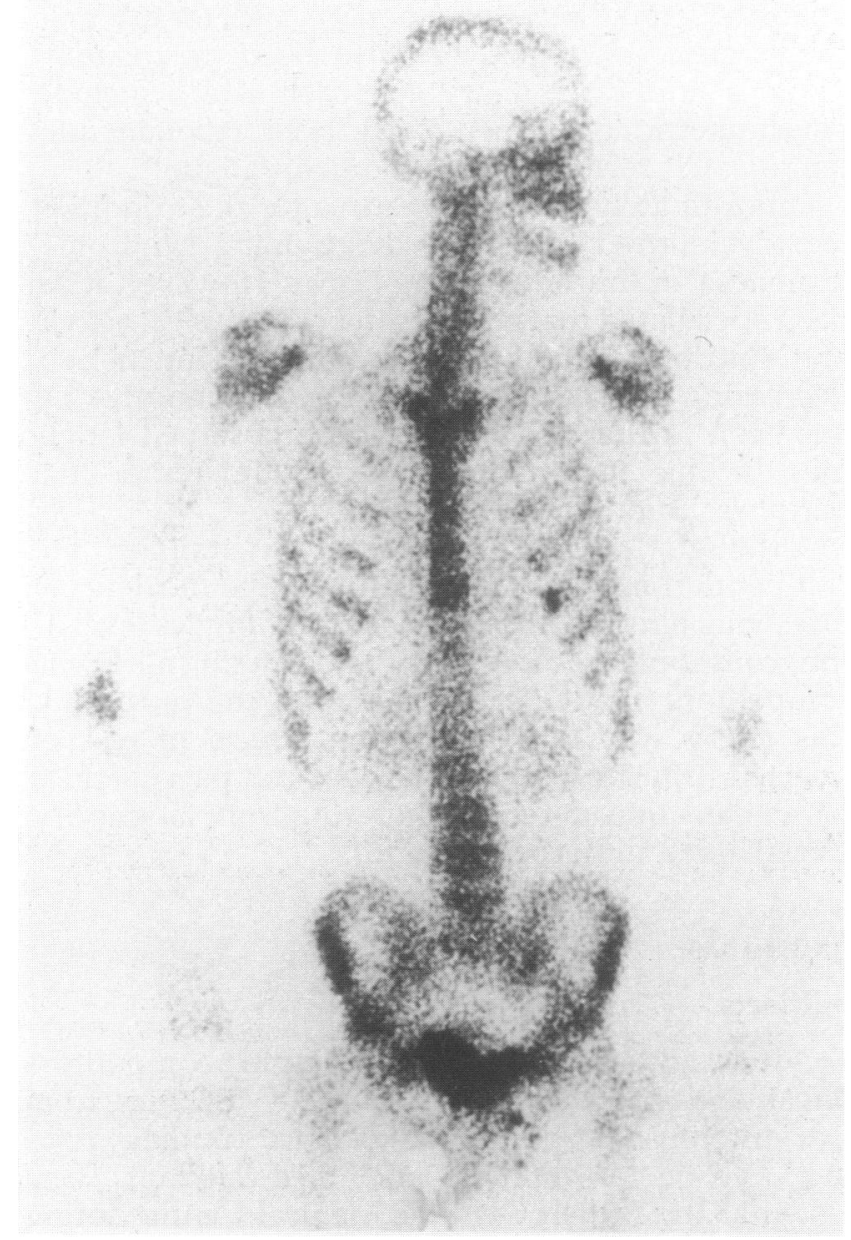

Figure 1. Tc $^{99}$ scan, anteroposterior view. A definite area of increased uptake is located on the sixth rib

Address for correspondence: N. Maffulli, Institute of Child Health, Respiratory and Anaesthetic Unit, Sports Medicine Laboratory, 30 Guildford Street, London WC1N 1EH, UK

(C) 1990 Butterworth-Heinemann Ltd 0306-3674/90/040247-01 the insertion of the left serratus anterior. His pain was reproduced by arm and trunk movements mimicking the canoeing stroke and stressing the serratus anterior against resistance. Plain radiograph was normal. A Tc ${ }^{99}$ scan showed increased uptake in the anterolateral portion of the left sixth rib (Figure 1) and a diagnosis of stress fracture was made.

After 4 weeks of cycling and jogging but no upper body training, gentle canoeing sessions were reintroduced and gradually increased over the next month without complaint. He resumed full training and competition and has now been asymptomatic for 12 months.

\section{Discussion}

Canoeing is a demanding non-weight-bearing sport taxing both aerobic and anaerobic metabolic pathways $^{1}$. The canoe stroke employs cyclic flexion, rotation, extension and flexion of the trunk and propulsive force is given by the arms. The paddling arm is flexed and lifted, the elbow moving away from the body, while the upper arm is lowered and moved towards the canoe. Fixation of the scapula during these movements is essential. No stress fractures have been reported in canoeists ${ }^{1}$ in contrast with studies showing rib stress fractures in rowers ${ }^{2,3}$.

Stress fractures of the ribs have been reported mainly in the first rib ${ }^{4,5}$ and in patients suffering from chest diseases ${ }^{6}$. In rowers, they have been described in two sites: posterolaterally in the proximity of the scapula and the ninth rib. $^{7}$. Stress fracture is rare in non-weight-bearing sports ${ }^{8}$.

\section{References}

1 Shephard, R.J. Science and medicine of canoeing and kayaking Sports Med 1987, 4, 19-33

2 Holden, D.L. and Jackson, D.W. Stress fracture of the ribs in female rowers Am J Sports Med 1985, 13, 342-348

3 McKenzie, D.C. Stress fracture of the rib in an elite oarsman Int J Sports Med 1989, 10, 220-222

4 Curran, J.P. and Kelly, D.A. Stress fracture of the first rib Am J Orthop 1966, 8, 16-18

5 Sacchetti, A.D., Beswick, D.R. and Morse, S.D. Rebound rib: stress-induced first rib fracture Ann Emerg Med 1983, 12, 177-179

6 Derbes, V.J. and Haran, T. Rib fractures from muscular effort with particular reference to cough Surgery 1954, 35, 294-321

7 Burrell, C.L., Burrell, R. Injuries in whitewater paddling. Phys Sportsmed. 1982, 10, 119-124

8 Hulkko, A., Orava, S. Stress fractures in athletes Int I Sports Med 1987, 8, 222-226 